Journal for the Cognitive Science of Religion

\title{
Advancing the Cognitive Science of Religion through Replication and Open Science
}

\author{
Suzanne Hoogeveen ${ }^{1}$ and Michiel van $\mathrm{Elk}^{2}$ \\ ${ }^{1}$ University of Amsterdam, Department of Social Psychology \\ ${ }^{2}$ Leiden University, Department of Cognitive Psychology
}

\begin{abstract}
The Cognitive Science of Religion (CSR) is a relatively young but prolific field that has offered compelling insights into religious minds and practices. However, many empirical findings within this field are still preliminary and their reliability remains to be determined. In this paper, we first argue that it is crucial to critically evaluate the CSR literature and adopt open science practices and replication research in particular to move the field forward. Second, we highlight the outcomes of previous replications and make suggestions for future replication studies in the CSR, with a particular focus on neuroscience, developmental psychology, and qualitative research. Finally, we provide a 'replication script' with advice on how to select, conduct, and organize replication research. Our approach is illustrated with a 'glimpse behind the scenes' of the recently launched Cross-Cultural Religious Replication Project, in the hope of inspiring scholars of religion to embrace open science and replication in their own research.
\end{abstract}

Keywords: Open Science, Replication, Cognitive Science of Religion

Science is associated with discovery, creativity, and innovation. Thinking outside the box is typically considered a hallmark of the scientific genius. For many researchers pursuing an academic career, it thus seems highly attractive to conduct new, creative studies, to invent new theories, and to postulate novel and crazy hypotheses; this will establish name

Suzanne Hoogeveen (D) https://orcid.org/0000-0002-1304-8615

Correspondence concerning this article should be addressed to: Suzanne Hoogeveen, Department of Psychology, PO Box 15906, 1001 NK Amsterdam, The Netherlands, E-mail: suzanne.j.hoogeveen@uva.nl. 
and fame and may result in publications in high-impact journals. Rigorous verification of existing theories and findings seems far less appealing. Although most scientists would agree that replication is essential for scientific progress, not all of them are eager to commit themselves to this ideal (Anderson et al., 2007; Baker, 2016). Replication research has the image of being 'boring', 'tedious', non-creative, and disadvantageous for one's career prospects (see for instance Yong, 2012).

Here, we propose a different perspective. First, we believe it is important to be critical of many 'classical' findings in the Cognitive Science of Religion (CSR). Whereas the replication crisis in psychology and neuroscience has dramatically altered the way of doing research, the impact beyond these fields remains yet to be determined. The CSR is a prime example of an interdisciplinary research field, in which scholars from different disciplinary backgrounds collaborate. Through this paper we hope to raise awareness of the importance of replication and open science practices, and to warn against the unwarranted acceptance of preliminary empirical findings. Below we will highlight some examples of high-impact studies in the CSR, most notably from the field of neuroscience and developmental psychology, that still await independent replication. We offer concrete suggestions on how the CSR should go about replicating these and other studies, including qualitative and field studies.

Second, we argue that as a field we should acknowledge the merits of open science in general, and replication studies in particular, in moving the CSR forward. Substantiating and validating existing theories and findings is more urgent than developing new 'grand theories' of religion. We should continue to encourage replication attempts in the CSR, and extend replication to different disciplines and methods.

Third, drawing on our own experience, we will exemplify that replication studies are in fact highly innovative, require a lot of creative thinking, and foster collaboration between (international) research groups. As such, this paper is meant to increase the enthusiasm for replication studies, implementing open science practices and fostering initiatives on these issues (e.g., through organizing special sections in journals, such as the Journal for the Cognitive Science of Religion; through calls for grants etc.).

\section{Call for Caution}

The year 2011 marked a tipping point in psychological science. The publication of a paper demonstrating the possibility of precognition through reverse priming (Bem, 2011), as well as the discovery of severe fraud in the work of social psychologist Diederik Stapel, instigated a process of critical internal scrutiny in psychology. While the Stapel case had a severe negative impact on the public credibility of psychological science, the Bem study was arguably more worrying as it demonstrated that even with good intentions and adherence to standard practices, psychological research could get derailed. The presented empirical evidence 
for extrasensory perception was, although statistically significant, in fact not compelling: Bem only provided weak evidence for the extraordinary claim that people can look into the future and did not specify an underlying causal mechanism (Wagenmakers et al., 2011). The study also raised questions about post-hoc hypothesizing and the blurred boundaries between confirmatory research and exploratory research ("fishing"); after seeing the data it may have seemed plausible that precognition only occurred for erotic pictures and extroverted people, but it is far from clear that this was an a priori hypothesis. Yet the real problem was arguably the lack of transparency in the research process; there was simply no way of knowing whether or not the results were fully anticipated or selectively reported. In retrospect, the study on precognition indeed shook psychological science on its foundations, yet not because the field universally accepted the idea of precognition. Instead, the Bem research made people realize that the then-standard research practices lacked rigor and failed to sufficiently inoculate researchers against human biases (e.g., confirmation bias and hindsight bias). Eventually, these issues created a distorted literature with spurious findings.

Attempts to map out the status of the field from a meta-perspective only further laid bare the deep-grained flaws in the methodology and the incentive structure that had become the norm in the field. Voiced issues included publication bias (significant results are more likely to be published than null-results; Francis, 2013), underpowered studies (Button et al., 2013 Ioannidis, 2005), and the ubiquity of questionable research practices such as selective reporting of (dependent) variables, of explored analysis paths, and of entire studies, creative inclusion/exclusion criteria, and post-hoc hypothesizing (John et al., 2012). Finally, warnings emerged concerning the lack of replication studies to determine the reliability, robustness, and stability of obtained findings (Makel et al., 2012, Schmidt, 2009). Later on, when these replication studies were conducted, they further demonstrated disturbingly low reproducibility rates of mainstream psychological findings (Camerer et al., 2018, R. Klein et al., 2014, R. Klein et al., 2018, Open Science Collaboration, 2012).

Fortunately, there is light at the end of the tunnel. This rather gloomy picture has inspired a wealth of colorful and creative initiatives to combat the 'crisis of confidence'. Accordingly, some open science advocates have proposed the terms "Credibility Revolution" (Vazire, 2018) or "Revolution 2.0" (Spellman, 2015), to emphasize the constructive reforms rather than focusing selectively on its causes. One popular approach aimed at selfcorrection in science is preregistration (Nosek \& Lindsay, 2018, Nosek et al., 2018; van 't Veer \& Giner-Sorolla, 2016). This practice entails the detailed delineation of the materials, methods, and analysis plan prior to data collection (see also Kavanagh \& Kapitany, 2017). Because the analysis pipeline cannot be tailored to the data, researchers protect themselves against hindsight and confirmation bias and other practices that may unwittingly bias 
the results (Wagenmakers et al., 2012). Additional open science initiatives focus on open databases and repositories to foster data sharing (e.g., the Open Science Framework; OSF), journal guidelines to promote transparency and reproducibility (PRO initiative; Nosek et al., 2015), novel publishing incentives that focus on quality of design rather than outcomes (e.g., the Registered Reports; Chambers, 2013), badges to award openness and transparency (Kidwell et al., 2016) 1 , and large-scale replication projects (Camerer et al., 2018, R. Klein et al., 2014: R. Klein et al., 2018. Open Science Collaboration, 2012). These replication efforts are not restricted to the field of psychology, but can also be found for instance in behavioral economics (Camerer et al., 2016) and empirical philosophy (Cova et al., 2018). Note that since there are numerous sources introducing general concepts of open science and its application in specific subfields, we will here restrict our focus on replication research. We refer the interested reader to Crüwell et al. (2019) for an accessible introduction and annotated reading list on open science practices in general, and to Charles et al. (2019) for an assessment of and recommendations for open science within the psychology of religion in particular (see also Table 1).

\section{Replication and the CSR}

The CSR has also started to embrace open science initiatives. Various labs now preregister their studies (e.g., Gervais et al., 2017; McPhetres, 2018, White et al., 2018), and data sharing has become far more common (e.g., Jong et al., 2019, Purzycki et al., 2018). At the same time, a recent systematic analysis of the 2017 issues from three psychology of religion journals found that none of the 53 included articles were preregistered (Charles et al., 2019). Furthermore, with regard to replication research, most studies conducted so far were aimed at replicating social psychological or priming studies (e.g., Gomes \& McCullough, 2015, Sanchez et al., 2017). While the debate is not yet settled (e.g., Shariff et al., 2016 van Elk et al., 2016), caution seems warranted regarding the reliability and robustness of some religious priming effects. Various replications of priming studies failed to find compelling evidence: subtle reminders of religion do not increase risk taking (based on the divine protection hypothesis; Gervais et al., 2020, Kupor et al., 2015), do not decrease grip endurance (based on the sexual and reproductive religiosity model; Hone \& McCullough, 2015, McCullough et al., 2012), religious priming does not increase dictator game allocations (based on the religion and prosociality link; Gomes \& McCullough, 2015, Shariff \& Norenzayan, 2007), and religious priming does not increase work ethic (based on the implicit puritanism account; Tierney et al., 2021, Uhlmann et al., 2011). In addition, analytical thinking primes do not decrease religiosity (Gervais \& Norenzayan, 2012; Sanchez et al., 2017) and threats

\footnotetext{
${ }^{1}$ Though the effectiveness of offering open science badges may not be unequivocal, at least for medical journals (Rowhani-Farid et al., 2020).
} 
to personal control do not increase belief in a controlling God (Hoogeveen et al., 2018; Kay et al., 2008). Keep in mind though, that these studies all concern social priming effects, the efficacy of which has been contested in general (Cesario, 2014; Doyen et al., 2012, Gilder \& Heerey, 2018; Pashler et al., 2013; Shanks et al., 2013). Thus, while these failed replications may appear disheartening for the scientific study of religion, we believe there are ample non-priming studies that may have a higher likelihood of successful replication.

We argue that open science practices, including replication studies should also be stimulated in other CSR-related fields, such as developmental research (e.g., intuitive dualism; Bloom, 2005, teleological thinking; Kelemen, 2004), the neuroscience of religion (e.g., neural correlates of religiosity; S. Harris et al., 2009, palliative effects of religious beliefs; Inzlicht et al., 2011, involvement of social brain areas in prayer; Schjoedt et al., 2009), and qualitative research approaches, including cultural anthropology, history, literary studies and religious studies. Indeed, these fields all face additional difficulties and challenges with regard to replication research.

One of the great merits of the CSR is the interdisciplinary nature of the research, which has successfully been advocated by various scholars of religion (Bulbulia, 2013; Bulbulia \& Slingerland, 2012 Slingerland \& Collard, 2011, Taves, 2010). In order to safeguard the CSR against unwarranted claims, we should put the open science principles into action across all sub-fields, by using the tools that were introduced to enhance replicability in the life and social sciences. At the same time, we should of course remain sensitive to the peculiarities of all sub-disciplines in the CSR. In the following sections we will outline the challenges associated with open science practices and replication research in neuroscience, developmental research, and qualitative research - fields of research that are of direct relevance for the CSR. We will present potential solutions and argue for the importance of taking these into account in moving the field of the CSR forward.

First, however, it is important to clarify the definition and scope of the term 'replication'. Often, a distinction is made between 'direct replications', in which the exact same study protocol is repeated in a new sample, and 'conceptual' replications', in which a different methodology is applied to test the same research hypothesis (e.g., Nosek \& Errington, 2017). These conceptual distinctions place much emphasis on methodological aspects and are arguably less relevant for non-experimental research. An alternative definition that emphasizes theoretical implications was recently proposed by Nosek and Errington 2020 , p.2): "Replication is a study for which any outcome would be considered diagnostic evidence about a claim from prior research. [...] To be a replication, 2 things must be true: outcomes consistent with a prior claim would increase confidence in the claim, and outcomes inconsistent with a prior claim would decrease confidence in the claim." Following this definition, replication research is part of the iterative process of theorizing, predicting, testing, and 
Table 1

Relevant Sources and Projects Related to Open Science and Replication for the Cognitive Science of Religion.

\begin{tabular}{|c|c|}
\hline \multicolumn{2}{|c|}{ Introduction to Open Science } \\
\hline $\begin{array}{l}\text { Crüwell et al. } \\
(2019) \\
\text { Charles et al. } \\
(2019)\end{array}$ & $\begin{array}{l}\text { Annotated reading list covering open data, preregistration and reg- } \\
\text { istered reports, replication research and more. } \\
\text { Assessment of OS practices in the CSR and recommendations for } \\
\text { scholars of religion. }\end{array}$ \\
\hline \multicolumn{2}{|c|}{ Collaborative (Replication) Projects } \\
\hline $\begin{array}{l}\text { Frank et al. } \\
(2017) \\
\text { Moshontz et al. } \\
(2018) \\
\text { Wagge et al. } \\
(2019)\end{array}$ & $\begin{array}{l}\text { ManyBabies, a global network for replications in developmental re- } \\
\text { search (osf.io/rpw6d). } \\
\text { Psychological Science Accelerator, a global laboratory network for } \\
\text { crowdsourcing research, including replications (psysciacc.org/). } \\
\text { Collaborative Research and Education Project (CREP), global net- } \\
\text { work for involving students in replication research }(\text { osf.io/wfc6u/). }\end{array}$ \\
\hline \multicolumn{2}{|c|}{ Open Science in Qualitative Research } \\
\hline $\begin{array}{l}\text { Tamminen and } \\
\text { Poucher }(2018) \\
\text { Bishop }(2 \overline{2009})\end{array}$ & $\begin{array}{l}\text { Practical advice on data sharing and re-use or replication in qualita- } \\
\text { tive research. } \\
\text { Discussion and advice on ethical data sharing and re-use in qualita- } \\
\text { tive research. }\end{array}$ \\
\hline \multicolumn{2}{|c|}{ Introduction to Bayesian Inference } \\
\hline Etz et al. (2018) & $\begin{array}{l}\text { Introduction of theoretical and practical concepts for researchers in- } \\
\text { terested in Bayesian statistics. }\end{array}$ \\
\hline $\begin{array}{l}\text { Wagenmakers, } \\
\text { Love, et al. }(2018)\end{array}$ & $\begin{array}{l}\text { Practical guide on conducting Bayesian analyses for various standard } \\
\text { tests in JASP (JASP Team, 2019). }\end{array}$ \\
\hline
\end{tabular}

Note. This is a non-exhaustive list of available interesting references and projects, that is mostly intended for the interested reader for further reference.

redefining theories in science. Furthermore, in many cases, it may be worthwhile to adopt a 'replication+' approach, in which the original study is repeated as closely as possible and extended in order to answer additional questions, by including new variables, conditions, samples, or studies (Bonett, 2012). This approach may present the best of both worlds by (dis)confirming existing findings and adding new insights or nuances.

\section{Replication Across Methods and Disciplines}

\section{Neuroscientific Research}

Neuroscience in general has been plagued with problems of low statistical power due to its reliance on expensive equipment and the time-intensive nature of data collection and 
analysis (Button et al., 2013, Szucs \& Ioannidis, 2017). This extensive process of data collection may limit the enthusiasm for conducting replication studies in neuroscience. A Web of Science search indicated that of all neuroscience articles published since 2010, only $0.08 \%$ contained the word 'replicate(d)' or 'replication' in the title, whereas this was $0.21 \%$ for all psychology articles. In addition, few neuroscience journals (6\%) explicitly state their interest in replication studies, lowering the incentives for conducting these studies even more (Yeung, 2017). For instance, Huber et al. (2019) describe their experience of attempting and eventually failing to publish a large replication study of neuroimaging work on memory retrieval that appeared in Nature Neuroscience (Potter et al., 2018, Wimber et al., 2015). In addition, the relatively few direct replication attempts that have been undertaken show exceptionally low replication rates. For instance, Boekel et al. (2015) attempted to replicate 17 brain-behaviour effects documented in the literature and found convincing support for only one out of 17 .

At the same time, it seems the field has become more aware of the importance of replication research, as evidenced for instance by special issues on replication (e.g., Barch \& Yarkoni, 2013; or a recent call from the Journal of Memory and Language). Efforts to collect and publicly share large neuroimaging data also contribute to increasing transparency in general and extending possibilities for conducting replication studies in particular. BotvinikNezer et al. (2019), for instance, collected a large dataset on decision making, initially aimed at quantifying analytical variability in neuroimaging research (Botvinik-Nezer et al., 2020), but the authors explicitly encourage researchers to use the data to assess replicability of specific findings within this paradigm. Other openly available neuroscience datasets are for instance those related to the Human Connectonome Project (wiki.humanconnectome.org/; Smith et al., 2013), or the EEG ManyLabs project (osf.io/yb3pq/).

\section{Prospects for Neuroscience Research in the CSR}

Neuroscientific studies have contributed substantially to the CSR, by fostering our understanding of the neurocognitive mechanisms underlying religious beliefs and experiences. As two illustrative examples, studies by Schjoedt et al. (2009) and Inzlicht et al. (2009) gave strong impetuses to the field by providing insights in the mechanisms underlying prayer experiences and conflict detection in religious believers, respectively. Schjoedt and colleagues (2009) used fMRI to demonstrate that brain areas involved in everyday social interaction and mentalizing are also activated when highly religious believers pray to God, substantiating articulated accounts of believers' personal relationship with God. Inzlicht and colleagues (2009) showed that religious believers exhibited a reduced neural response to errors on a Stroop task, potentially reflecting the palliative effects of religiosity on distress responses. Although different interpretations of the results have been put forward (Schjoedt \& Bulbu- 
lia, 2011), these findings have sparked a debate in the CSR on the relevance of neuroimaging for research on religion and spirituality more generally (Schjoedt \& van Elk, 2019).

Both of these studies have in fact been subjected to replication attempts. First, the study by Schjoedt et al. (2009), in which Danish Christians participated, was successfully replicated in an American Pentecostal sample (Neubauer, 2014). While replicating the finding that personal prayer involved brain regions related to social cognition, the replication also extended the original study, by showing substantial overlap in neural activation between personal prayer and talking to a loved one. This was taken to indicate that communication with God through prayer and interaction with a real person rely on similar neurocognitive processes related to mentalizing. Second, with respect to the Inzlicht et al. (2009) study, we recently failed to conceptually replicate the main results (Hoogeveen, Snoek, et al., 2020). Using data from 193 subjects, we found no association between religiosity and conflict sensitivity, neither at a behavioral nor at a neural level, casting doubt on the reliability of these previous findings. Similarly, van Elk and Snoek (2020) found no evidence for the relation between religiosity and grey matter volume in several brain areas that were identified in the literature as being associated with religiosity or mystical experiences. Both these datasets, as well as the overall neuroimaging project data they were a part of, are publicly available and we happily invite researchers to explore whether these data may contribute to answering additional questions in the CSR $\mathrm{L}^{2}$

Notably, some of the seminal neuroscientific studies on religiosity are illustrative of oldschool research practices: with samples of $n=28 ; n=22$ (between-subjects; Inzlicht et al., 2009), $n=30$ (between-subjects; S. Harris et al., 2009), and $n=36$ (between-subjects; Schjoedt et al., 2011) these studies are most certainly underpowered, and thus potentially unreliable. Importantly, while samples of 20-30 participants may suffice in within-subjects designs with many trials per person, they are most likely inadequate for detecting reliable between-subjects effects or individual differences which are typically targeted in the cognitive science of religion, e.g., comparing religious individuals to non-religious individuals or atheists. Indeed, researchers often overestimate the power achieved in these between-subject designs, especially for small effects (Bakker et al., 2016). In general, it may be difficult to formulate standard guidelines for adequate sample sizes as power depends on the specific design and expected effect size. Nevertheless, some have recommended a minimum sample size of $N=100$ for correlational (neuroimaging) reserach (Dubois \& Adolphs, 2016; Schönbrodt \& Perugini, 2013).

\footnotetext{
${ }^{2}$ For the overall neuroimaging project data, see Snoek et al. (2020). For the religiosity and conflict sensitivity study: The preprocessing scripts for the fMRI analysis and the exploratory fMRI analyses can be found at https://github.com/lukassnoek/ReligiosityFMRI. Unthresholded brain maps can be found at https://neurovault.org/collections/6139/. For the structural brain differences and religiosity study: All analysis code can be found at https://github.com/lukassnoek/ReligiosityVBM. Unthresholded brain maps from the whole-brain analysis can be found at https://neurovault.org/collections/5380
} 
In light of these concerns, we recommend conducting high-powered replication attempts of key neuroscientific studies on religiosity, such as those mentioned above, as these findings had a strong impact on theory development in the field. Replicators could for example, repeat the work by S. Harris et al. (2009) investigating the neural correlates of religious and non-religious beliefs. An interesting extension would also be to apply multi-voxel pattern analysis (MVPA) to provide insight into how religious concepts are distributed and represented among different brain regions, and compare patterns of brain activation coding for religious agents (e.g., God, angel), for imaginary agents (e.g., Santa Claus, Superman) and for real people (e.g., Napoleon, Bill Gates; cf. Leshinskaya et al., 2017). This would allow one to determine to what extent there is an overlap between the neural representation of real and supernatural agents. In addition, it would be important to establish to what extent these findings generalize across different cultural settings and different religions (e.g., do Muslims show the same pattern of social cognition-related brain activity during prayer as orthodox Christians?).

\section{Developmental Research}

Similar to neuroscience, the field of developmental psychology has seen many underpowered studies, mostly due to difficulties in recruiting a sufficient number of children or babies (Frank et al., 2017; Schott et al., 2018). This is further complicated by the fact that in most developmental studies there is a high dropout rate, due to fuzziness or distraction of the child. In addition, researchers typically rely on indirect measures of cognition, such as heart rate, EEG responses or gaze pattern (Cristia et al., 2016). Although useful and providing interesting insight into the early stages of cognitive development, there is the recurring problem of providing 'rich interpretations' of the data that are not fully warranted in light of the empirical evidence (Haith, 1998).

So how can we remedy these problems? Developmental research always faces a challenge in terms of subject recruitment and testing, but many hands can make light work. Large-scale collaborative (replication) efforts can play a pivotal role in advancing this field. A notable initiative is for instance the ManyBabies project, which specifically aims to set up multi-lab replication studies to investigate the developmental trajectory of key phenomena such as theory of mind reasoning and infant-directed speech (Frank et al., 2017; see project details via osf.io/rpw6d). The first project, for instance, successfully replicated infants' preference for infant-directed speech over adult-directed speech, and identified developmental, cultural and methodological moderators (Consortium, 2020). While the findings of these projects may be interesting for the cognitive science of religion on their own (e.g., how does theory of mind develop? How and when do children distinguish between objects with agency and no agency?), ManyBabies also serves as an example on how to set up large scale 
collaborative projects for other developmental findings. The fact that these many-labs style projects enable cross-cultural data collection may be especially valuable for the cognitive science of religion, which also aims to unravel the potential universal cognitive precursors underlying supernatural beliefs.

\section{Prospects for Developmental Research in the CSR}

The way children develop an understanding of other minds, including God's mind, and believe in an afterlife provides an important argument for the naturalness of religion theory (Barrett, 2000, Bloom, 2007). Although popular, this account has been criticized for ignoring the role of cultural learning and religious upbringing (Banerjee \& Bloom, 2013; Corriveau et al., 2015 Evans, 2001; Gervais et al., 2011; P. Harris \& Giménez, 2005). The ongoing debate in this domain (e.g., Barrett, 2018; Sterelny, 2018), further stresses the need for critical evaluation and replication of cornerstone studies, including developmental studies on supernatural mind representation (Barrett et al., 2003 Barrett et al., 2001), teleological thinking (Kelemen, 2004), and mind-body dualism (Bering, 2006). Notably, Makris and Pnevmatikos (2007) conducted a replication of the study by Barrett et al. (2001), in which the authors challenged the finding that the understanding of God's mind precedes the development of theory of mind reasoning about humans. As the debate on the naturalness of religion critically hinges on this type of developmental research, replication of these seminal studies is crucial. Replication studies comparing children from different ages across secular and religious cultures could for instance shed light on the central question whether religious cognition (including dualistic and teleological reasoning) indeed 'comes natural' to children.

\section{Qualitative Research}

Field studies and qualitative research have made important contributions to the scientific study of religion, for instance, by providing anthropological records of religious communities (e.g., Barrett, 1998, Power, 2017, Schjoedt et al., 2013, Whitehouse \& Lanman, 2014), historical analyses of the cultural evolution of religions (e.g., Norenzayan et al., 2016, Wright, 2010), and phenomenological accounts of religious experiences and rituals (e.g., Hardy, 1981; Luhrmann, 2012; Taves, 1999).

Replication and open science are contentious topics in qualitative research and the humanities. Next to the question of when and how to enhance reproducibility, scholars have also raised precursory questions of whether replication is even possible and desirable in the humanities. Below we argue that replication is important for any research project that involves empirical data, and thus also for many - though not all - qualitative studies. 


\section{Conceptual considerations}

Proponents of replication studies in the humanities have pointed out that much research in the humanities is empirical in nature (Peels \& Bouter, 2018a). Conceptually, being able to answer a question by using the same or similar methods under the same or similar circumstances, is desirable in any scientific field (Peels \& Bouter, 2018b). As such, replication should be a pillar in the humanities as well as in the other sciences. Others appear less enthusiastic. In a recent statement in Nature with the title "Resist calls for replicability in the humanities", de Rijcke and Penders (2018) argue that the quality criteria for research are fundamentally different between the (natural) sciences and the humanities. According to the authors, the study objects of the humanities are embedded in a dynamically evolving culture, and therefore by definition cannot be studied separate from the original context (as a replication study implies).

Indeed, qualitative research typically provides an in-depth analysis of a specific study object, which in turn constrains the scope and generalizability of the study. This does not however, preclude replication. Payne and Williams (2005), for instance, argue that humanities often implicitly or explicitly employ "moderatum generalizations" in their research. These are moderate generalizations in terms of the scope of what is claimed and the strength of belief in the claim. These generalizations do not imply universality but have relevance beyond their immediate object, and are presented as hypotheses rather than facts. It is the task of the researcher to explicitly specify the conditions and to demarcate the line between data and interpretation (Payne \& Williams, 2005). As argued by Anczyk et al. (2019), replication can be used to verify the "moderatum generalizations" under the assumed conditions, or to investigate how changes in context affect the conclusions. This kind of conceptual replication is indeed recommended to increase reproducibility in the humanities (Peels \& Bouter, 2018a). As new data cannot always be acquired, the potential for direct replication in qualitative research is limited. Conceptual replication and triangulation - approaching a claim using independent lines of evidence and different methods

- may better serve this purpose (Munafò \& Smith, 2018; Peels \& Bouter, 2018a). Note that especially with respect to qualitative research, the distinction between replication and generalization may become fuzzy. However, following the broad definition as proposed by Nosek and Errington (2020), generalization to different contexts can also be considered replication, as long as the original claim presupposes an effect across different contexts, including the newly targeted one.

As argued by Tamminen and Poucher (2018), while some may consider the rationale for engaging in open science problematic for qualitative research, implementing practices could be relatively straightforward. In other words, if qualitative researchers want to commit to adopting open science in their work, they could relatively easily do so. We refer the 
interested reader to Tamminen and Poucher (2018) and Bishop (2009), who address various ethical concerns and provide practical advice on data sharing and re-use or replication in qualitative research (see also Table 1).

\section{Illustrations from the CSR}

Examples from the CSR can exemplify the conceptual and practical concerns related to replicating studies from anthropology and the humanities. For instance, conducting a direct replication of the findings from a Spanish fire-walking ritual (Konvalinka et al., 2011) in Finland, seems silly and invalid, as Finnish people most likely do not engage in fire-walking rituals. However, the underlying conclusions of synchronized arousal contributing to social cohesion can very well be replicated in a sample of practitioners of the high-arousal Brazilian Jiu Jitsu material arts (it did not exactly replicate; Kavanagh et al., 2018) or perhaps in the Finnish ritual of 'wife-carrying' (Eukonkanto, see wikipedia.org/wiki/Wife-carrying; we happily invite researchers to subject this practice to a replication attempt).

Another example may be found in Slingerland and Chudek (2011), who argue for the presence of folk dualism beliefs in early Chinese culture on the basis of the analysis of historical texts from ancient China (pre-221 BCE). Unless considerable new bodies of text from more than 2000 years ago are discovered, a direct replication seems fruitless here as well. One could, however, draw from different sorts of evidence to investigate the same question for the same population, i.e., conduct a conceptual replication by using a process of triangulation. Pan (2017), for example, used archaeological records of traditional medical practices to shed light on early Chinese mind-body dualism - and reached a different conclusion than Slingerland and Chudek (2011).

The idea of making "moderatum generalizations" and subsequently testing these is also nicely illustrated by the work of Luhrmann (2005, 2012). On the basis of field work and interviews with members of the evangelical Vineyard Christian church in Chicago and Palo Alto, she describes and interprets the primary data. The overall aim is to learn something more general about the way in which believers come to experience the supernatural as real. One of her conclusions reads for instance as follows: "Perhaps the most novel suggestion here $[. .$.$] is that there may be a shared psychological mechanism - absorption - in the$ psychiatric response to trauma and in spiritual experience, that the individual capacity for absorption can be trained, and that cultural interest in that training can rise and fall at different times." (Luhrmann, 2005, p.154). The 'absorption hypothesis' has also been tested in groups of participants from India and West-Africa - even though it would not qualify as a 'direct replication' (Luhrmann et al., 2015). This work demonstrates the value of replication beyond confirming or rejecting the original theory and study. By showing both similarities in underlying process and differences in particular content, this research 
has made significant theoretical contributions to the CSR literature.

\section{A Glimpse Behind the Scenes \& A Replication Script}

Translating these ideas into action, we recently set up direct replication and conceptual replication studies on CSR-related topics. In addition to previously mentioned replications of the link between personal control and belief in a controlling God (Hoogeveen et al., 2018; Kay et al., 2008) and cognitive control sensitivity and religiosity (Hoogeveen, Snoek, et al., 2020, Inzlicht et al., 2009), we launched the cross-cultural religious replication project (CCRRP), a large-scale collaborative project (see www.relcoglab.com/religious-replicationproject). We believe a glimpse behind the scenes of this project may illustrate and crystallize our idea that replication can be fun, challenging, innovative and it can create great opportunities for collaboration. Below, we provide a 'replication script' with recommendations and tips for conducting replication research in the CSR, building on our experiences with the CCRRP (see also Table 2 on page 15).

\section{Selecting}

First off, deciding which study to select for replication out of the vast literature can be both exciting and fun. We argue that the a priori likelihood of replicability should be taken into account. Assessment of the added value of replication studies, for example by looking at informational gain, is an important first step. For our project, conversations with the project committee highlighted that we should opt for studies with medium chances of being successfully replicated, as these are most interesting and informative. This notion of information gain can be formalized in a Bayesian framework (Hardwicke, Tessler, et al., 2018), but it basically follows a simple intuition: especially for original studies with highly surprising effects (i.e., low prior odds) or small sample sizes (i.e., little evidence; little posterior updating) replications can bring about considerable informational gain. The value of intuitions about a priori chances of replication success is corroborated by recent prediction market studies (e.g., Camerer et al., 2018, Dreber et al., 2015; Forsell et al., 2018; Tierney et al., 2021). In these studies, researchers in psychology were asked to estimate and bet money on the outcomes of large-scale replication projects such as Many Labs 2 (R. Klein et al., 2018) and the Science and Nature Replications (Camerer et al., 2018). Interestingly, prediction market bets and survey beliefs about the likelihood of a study being replicated, were highly correlated with actual replication effect sizes (see also https://replicats.research.unimelb.edu.au/ for more information on prediction markets studies). It thus seems important to discuss the selection of to-be-replicated studies with experts in the field beforehand, as their intuitions may be informative (although it seems that even laypeople can to some extent predict replication outcomes; Hoogeveen, Sarafoglou, 
et al., 2020).

For the CCRRP, we particularly aimed to conduct conceptual replications of influential theories and effects in the psychology of religion that are relevant to be studied crossculturally. In general, we could recommend the 'replication+' approach, as it not only reinforces previous findings, but can also offer interesting new data and perspectives. For instance, multi-lab projects can assess the cross-cultural universality or variability plus boundary conditions of some phenomenon. A relevant illustration of such a replication+ approach can be found in the project by Tierney et al. (2021), in which a 'creative destruction approach to replication' is adopted. Here, the original hypothesis is not only compared to the null-hypothesis, but also to various alternative theoretically relevant accounts. This work tested the implicit puritanism theory which holds that Americans are unique in their implicit moralization of work and the link between work and sex ethics, as a heritage of Puritan-Protestant settlers (Uhlmann et al., 2009; Uhlmann et al., 2011). The replication found evidence for some core effects, yet these effects emerged across all included cultures instead of exclusively in the US. For instance, targets who continued working after winning the lottery were evaluated more positively than targets who retired (i.e., a moral praise of needless work effect), and lazy targets are more often misremembered as promiscuous compared to hard-working targets (and vice versa; a tacit sex and work link effect). In other words, while previous effects were not replicated successfully according to the most stringent criteria for replication because no cultural differences were found, the study did boost confidence for the -potentially universal- presence of some of the general effects and provided new theoretical insights.

\section{Planning}

Once settled on a target study and potential extension, we would advise to reach out for collaborations. In our experience, many researchers in the CSR / psychology of religion that we approached were enthusiastic and eager to collaborate on projects like this. In general, we believe the ideal of collaborative science is increasingly embraced by the scientific community (Chartier et al., 2018), as evidenced by the proliferation of large collaborative projects such as ManyLabs (Ebersole et al., 2016 R. Klein et al., 2014; R. Klein et al., 2018), ManyBabies (Consortium, 2020 Frank et al., 2017), and the Psychological Science Accelerator (Moshontz et al., 2018). For direct replication attempts it may also be relevant to invite authors who were involved in the original study, in order to optimize the study design and to avoid getting into an argument after the study has been conducted. We had a very good experience of conducting a direct replication in collaboration with the original author for Hoogeveen et al. (2018), in which we failed to replicate the original findings. However, we are also aware of post-hoc disputes about replication outcomes, for instance in relation to the ManyLabs 
Table 2

Replication Script

\begin{tabular}{ll}
\hline Stage & Recommendation \\
\hline Selecting & Opt for studies with medium chances of replication success. \\
& Consult experts in the field for their suggestions and intuitions. \\
& Investigate possibilities for replication+ projects that replicate and extend \\
& previous work in interesting ways (e.g., boundary conditions or cross- \\
& cultural universality). \\
& Possibly: seek collaboration with colleagues in the field, for instance with \\
Planning & authors of the original study. \\
& In cross-cultural projects: ask for feedback on cultural appropriateness of \\
& experimental materials. \\
& Preregister the research questions, hypotheses, methods, and analysis \\
& plan. \\
& Consider a Registered Report format. \\
& Collect data. \\
& Possibly: use analysis blinding to retain flexibility yet avoid biases. \\
Executing & Conduct analyses according to preregistered plan, and explore data for \\
& interesting patterns. \\
Write up results and invite discussions from scholars in the field. \\
Share annotated data and code.
\end{tabular}

Note. This script was inspired by the summary of guidelines reported in van Doorn et al. (2020).

4 replication of the mortality salience effect: the replicators reported replication failure, proponents of the theory concluded that the effect was meaningfully present in one specific preregistered subgroup, and critics argued that there was strong overall evidence against the effect and no evidence for the specific subgroup. (Chatard et al., 2020; Haaf et al., 2020; R. Klein et al., 2019).

Besides sharing costs and effort, another advantage of multi-lab studies is that more diversity in the populations for data collection is achieved. International collaboration will likely also benefit the quality of the study design and will optimize choices for the phrasing of different questions, statements and stimuli. For instance, we were confronted with the cultural-specificity vs. universality dilemma in the creation of the stimuli for our project. Measures of religious beliefs and behaviours require considerable cultural fine-tuning. Our advice would be to use cross-culturally validated questionnaires and stimulus material where possible. Alternatively, it would be wise to consult scholars in the respective countries and field sites. As an example, we had discussions with an anthropologist whether it would make sense to use the same photographic stimulus of an "ethnically ambiguous-looking person" across all countries - it would not (see Figure 1 for an example of the culture-specific stimuli 


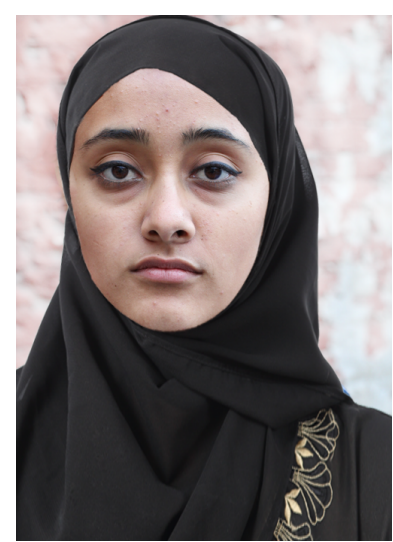

(a) Religious stimulus

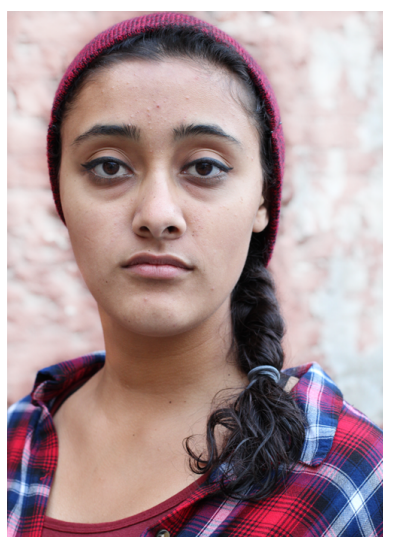

(b) Control stimulus

Figure 1

Example stimuli of a religious and non-religious looking female for Arabic countries as used in the Cross-Cultural Religious Replication Project.

that were subsequently created for the CCRRP). Familiarity with the target population and the possibility to provide feedback with this knowledge in mind can probably improve the study validity substantially. In our case, it most certainly did.

As mentioned before, for any replication study the research questions, hypotheses, methods, and analysis plans should be preregistered. For a detailed argument and guidelines on preregistration, see Kavanagh and Kapitany (2017) in this issue. The format of a Registered Report may be especially suitable for replication projects (i.e., a 'triple R'). Here, the preregistration is integrated with the peer-review process; the introduction, methods, and proposed analysis plan are reviewed prior to data collection (Chambers, 2013). Upon approval by the reviewers and editor, the study proposal can receive In-Principle Acceptance, allowing it to be published regardless of the eventual study outcomes. Note that the International Journal for the Psychology of Religion, Archive for the Psychology of Religion, and Psychology of Religion and Spirituality now also offer the Registered Report format (van Elk, 2019).

\section{Executing}

While a preregistration requires one to specify design and analysis choices beforehand, in practice, often one still has to deviate from the plan when conducting the actual data analysis. A recent investigation found that in fact 27 out of 27 preregistered studies published in Psychological Science deviated from their corresponding plan (Claesen et al., 2019). Deviations are not by definition problematic, as there may be valid reasons to change plans, as long as they are transparently reported (DeHaven, 2017). Indeed, we already anticipate deviations from our preregistration for the CCRRP, which we will describe and justify in a 
separate sub-section of any eventual paper.

In the current project, we also incorporated an additional protective layer against any unconscious data-driven bias affecting the results, namely the notion of blinded analyses. We believe this can be of interest in many (large-scale) replication projects, or any study for that matter. Analysis blinding involves the temporary distortion of certain aspects of the data, for example by masking condition labels, adding noise, or shuffling key variables in the data (Dutilh et al., 2019, MacCoun \& Perlmutter, 2015). It has been argued that the combination of preregistration and analysis blinding may present an optimal balance between transparency, rigor, and flexibility (MacCoun \& Perlmutter, 2015). The crucial idea is that with blinded data, analyses can be conducted flexibly without the risk of contamination by (unintentional) confirmation biases and significance seeking, because the actual outcomes are hidden from the analyst. In the first phase, analyses can be adjusted to unexpected peculiarities in the blinded data, thereby retaining desirable flexibility that may be lost with strictly following the preregistered analysis plans. Only after the data analyst is satisfied with preprocessing and model specification (e.g., outlier removal, choosing the appropriate statistical model given its assumptions), the blind is lifted and the real data are analyzed in the final model. In addition to running prespecified confirmatory analyses, rich data sets may also be used for exploratory analyses - as long as the distinction between confirmatory and exploratory analyses is not blurred.

With respect to data analysis, we would additionally recommend the use of Bayesian statistics in the scientific study of religion (van Elk \& Wagenmakers, 2017). We believe the benefits of using a Bayesian approach are huge: Bayesian statistics are intuitive and can easily be implemented with freely available and user-friendly tools such as JASP (JASP Team, 2019). General advantages include the fact that instead of dichotomizing results as 'significant' vs. 'non-significant', Bayes factors can quantify evidence on a continuous scale and distinguish between "absence of evidence" and "evidence of absence" (Dienes, 2014; Wagenmakers, Marsman, et al., 2018). Furthermore, Bayesian statistics provide an effective method to optimize data efficiency and analysis quality. This is especially advantageous for data collection in hard-to-reach populations such as young children and small-scale societies or data that relies on expensive materials and testing settings such as neuroscience studies (Nakagawa \& Hauber, 2011). In contrast to frequentist statistics, in Bayesian inference, online monitoring of the evidence does not inflate Type I error rates (Rouder, 2014. Wagenmakers, Marsman, et al., 2018). That is, if there is no effect, the p-value will randomly fluctuate between 1 and 0 . So the more often one inspects the data, the higher the chance that at some point the p-value will be lower than .05. In the Bayesian framework, however, if there is no effect, the posterior model odds and Bayes factor will drift towards more and more evidence for the null-model, relative to the alternative model 
(see the preprint by Wagenmakers et al., 2019 for an accessible explanation of the stopping rule principle in Bayesian inference). We refer the interested reader to Etz et al. (2018) for an introduction to Bayesian inference and to Wagenmakers, Love, et al. (2018) for a demonstration of Bayesian analyses for various standard statistical tests such as the $t$-test, ANOVA, contingency tables, and regression.

\section{Reporting}

Finally, a cornerstone of reproducible science is that it is indeed comprehensibly reproducible. Issues with messy, illegible analysis scripts or nonfunctional data formats (e.g., a .pdf file) are prevalent, even with openly shared data (Hardwicke, Mathur, et al., 2018). Careful annotation of data files (i.e., meaningful variable names or an accompanying codebook), analysis scripts (preferably in open-source programs) and workflow is essential for reproducible science (e.g., Gilmore et al., 2018, Wilkinson et al., 2016). The initiative GO FAIR (www.go-fair.org/) picks up on this observation and aims to assist researchers in implementing the FAIR data principles of making data Findable, Accessible, Interoperable, and Reusable (Wilkinson et al., 2016).

\section{Conclusion}

We realize that the presented recommendations and suggestions may be somewhat overwhelming for researchers that are new to the open science movement. Far from suggesting that scholars in the CSR should completely revolutionize their workflow and adopt all outlined open science practices overnight, we instead invite researchers to try it out. For instance, start by sharing the data of a just-finished project (see Gewin, 2016, O. Klein et al., 2018 for practical advice), or consider submitting unpublished null-findings as a file-drawer report to this journal (JCSR; see this call). Whereas launching a large-scale replication project may be beyond one's reach, consider first joining an existing project (e.g., via the Psychological Science Accelerator; https://psysciacc.org/. Another possibility is to integrate replication research with the student curriculum. For instance, the Collaborative Replications and Education Project (CREP; http://osf.io/wfc6u) is an international framework that allows students to work together on conducting direct replications of recent impactful studies (Wagge et al., 2019). This way, the initiative both serves an educational purpose and allows supervisory researchers to get a taste of the replication process and contribute to establishing the reliability of the literature.

Much attention has been paid to large-scale multi-lab replication projects that included various classical effects from psychological studies (e.g., Camerer et al., 2018; R. Klein et al., 2014 Open Science Collaboration, 2015). These projects provided the necessary impetus to fan the flames of the credibility revolution. At the same time, we would like to emphasize 
the importance of expert scholars actually conducting replication studies in their domain of expertise. Lack of theoretical and methodological knowledge should not be exploited as a valid or invalid - excuse for replication failure. Moreover, active proponents of replication research are sometimes reproached for taking a skeptical or even cynical stand a priori, i.e., being motivated to show replication failure, rather than success. Therefore, replications should also be conducted by 'expert insiders'.

We would thus like to encourage the community of CSR scholars to take action and invite them to join the bandwagon of open science and replication research. Doing replication studies is innovative, challenging, exciting and it provides a valuable learning experience for all involved.

\section{References}

Anczyk, A., Grzymala-Moszczyńska, H., Krzysztof-Swiderska, A., \& Prusak, J. (2019). The Replication Crisis and Qualitative Research in the Psychology of Religion. The International Journal for the Psychology of Religion, 29, 278-291. https://doi.org/10. 1080/10508619.2019.1687197

Anderson, M. S., Martinson, B. C., \& De Vries, R. (2007). Normative Dissonance in Science: Results from a National Survey of U.S. Scientists. Journal of Empirical Research on Human Research Ethics, 2, 3-14. https://doi.org/10.1525/jer.2007.2.4.3

Baker, M. (2016). Is There a Reproducibility Crisis? Nature, 533, 452-454.

Bakker, M., Hartgerink, C. H. J., Wicherts, J. M., \& van der Maas, H. L. J. (2016). Researchers' Intuitions About Power in Psychological Research. Psychological Science, 27, 1069-1077. https://doi.org/10.1177/0956797616647519

Banerjee, K., \& Bloom, P. (2013). Would Tarzan believe in God? Conditions for the emergence of religious belief. Trends in Cognitive Sciences, 17, 7-8. https://doi.org/10. 1016/j.tics.2012.11.005

Barch, D. M., \& Yarkoni, T. (2013). Introduction to the special issue on reliability and replication in cognitive and affective neuroscience research. Cognitive, Affective, \& Behavioral Neuroscience, 13, 687-689. https://doi.org/10.3758/s13415-013-0201-7

Barrett, J. L. (2000). Exploring the natural foundations of religion. Trends in Cognitive Sciences, 4, 29-34. https://doi.org/10.1016/S1364-6613(99)01419-9

Barrett, J. L. (2018). Some common misunderstandings about cognitive approaches to the study of religion: A reply to Sterelny. Religion, Brain $\&$ Behavior, 8, 425-428. https: //doi.org/10.1080/2153599X.2017.1323787

Barrett, J. L., Newman, R. M., \& Richert, R. (2003). When Seeing Is Not Believing: Children's Understanding of Humans' and Non-Humans' Use of Background Knowledge 
in Interpreting Visual Displays. Journal of Cognition and Culture, 3, 91-108. https: //doi.org/10.1163/156853703321598590

Barrett, J. L., Richert, R. A., \& Driesenga, A. (2001). God's Beliefs versus Mother's: The Development of Nonhuman Agent Concepts. Child Development, 72, 50-65. https: //doi.org/10.1111/1467-8624.00265

Barrett, J. L. (1998). Cognitive constraints on Hindu concepts of the divine. Journal for the Scientific Study of Religion, 608-619. https://doi.org/10.2307/1388144

Bem, D. J. (2011). Feeling the Future: Experimental Evidence for Anomalous Retroactive Influences on Cognition and Affect. Journal of Personality and Social Psychology, 100, 407-425. https://doi.org/10.1037/a0021524

Bering, J. M. (2006). The folk psychology of souls. Behavioral and Brain Sciences, 29, 453462. https://doi.org/10.1017/S0140525X06009101

Bishop, L. (2009). Ethical Sharing and Reuse of Qualitative Data. Australian Journal of Social Issues, 44, 255-272. https://doi.org/10.1002/j.1839-4655.2009.tb00145.x

Bloom, P. (2005). Descartes' baby: How the science of child development explains what makes us human. Random House.

Bloom, P. (2007). Religion is natural. Developmental Science, 10, 147-151. https://doi.org/ 10.1111/j.1467-7687.2007.00577.x

Boekel, W., Wagenmakers, E., Belay, L., Verhagen, A. J., Brown, S. D., \& Forstmann, B. (2015). A purely confirmatory replication study of structural brain-behavior correlations. Cortex, 66, 115-133. https://doi.org/10.1016/j.cortex.2014.11.019

Bonett, D. G. (2012). Replication-Extension Studies. Current Directions in Psychological Science, 21, 409-412. https://doi.org/10.1177/0963721412459512

Botvinik-Nezer, R., Holzmeister, F., Camerer, C. F., Dreber, A., Huber, J., Johannesson, M., Kirchler, M., Iwanir, R., Mumford, J. A., Adcock, R. A., Avesani, P., Baczkowski, B. M., Bajracharya, A., Bakst, L., Ball, S., Barilari, M., Bault, N., Beaton, D., Beitner, J., ... Schonberg, T. (2020). Variability in the analysis of a single neuroimaging dataset by many teams. Nature, 582, 84-88. https://doi.org/10.1038/s41586-0202314-9

Botvinik-Nezer, R., Iwanir, R., Holzmeister, F., Huber, J., Johannesson, M., Kirchler, M., Dreber, A., Camerer, C. F., Poldrack, R. A., \& Schonberg, T. (2019). fMRI data of mixed gambles from the Neuroimaging Analysis Replication and Prediction Study. Scientific Data, 6, 106. https://doi.org/10.1038/s41597-019-0113-7

Bulbulia, J. (2013). The arts transform the cognitive science of religion. Journal for the Cognitive Science of Religion, 1, 141. https://doi.org/10.1558/jcsr.v1i2.141 
Bulbulia, J., \& Slingerland, E. (2012). Religious studies as a life science. Numen-international Review for The History of Religions, 59, 564-613. https:// doi.org/10.1163/ 15685276-12341240

Button, K. S., Ioannidis, J. P. A., Mokrysz, C., Nosek, B. A., Flint, J., Robinson, E. S. J., \& Munafò, M. R. (2013). Power failure: Why small sample size undermines the reliability of neuroscience. Nature Reviews Neuroscience, 14, 365-376. https://doi. org/10.1038/nrn3475

Camerer, C. F., Dreber, A., Holzmeister, F., Ho, T., Huber, J., Johannesson, M., Kirchler, M., Nave, G., Nosek, B., Pfeiffer, T., Altmejd, A., Buttrick, N., Chan, T., Chen, Y., Forsell, E., Heikensten, E., Hummer, L., Imai, T., Isaksson, S., .. Wu, H. (2018). Evaluating Replicability of Social Science Experiments in Nature and Science. Nature Human Behaviour, 2, 637-644.

Camerer, C. F., Dreber, A., Ho, T.-H., Huber, J., Johannesson, M., Kirchler, M., Almenberg, J., Altmejd, A., Chan, T., Heikensten, E., Holzmeister, F., Imai, T., Isaksson, S., Nave, G., Pfeiffer, T., \& Razen, M. (2016). Evaluating replicability of laboratory experiments in economics. Science, 351, 1433-1436. https://doi.org/10.1126/ science.aaf0918

Cesario, J. (2014). Priming, replication, and the hardest science. Perspectives on Psychological Science, 9, 40-48. https://doi.org/10.1177/1745691613513470

Chambers, C. D. (2013). Registered Reports: A New Publishing Initiative at Cortex. Cortex, 49, 609-610. https://doi.org/10.1016/j.cortex.2012.12.016

Charles, S. J., Bartlett, J. E., Messick, K. J., III, T. J. C., \& Uzdavines, A. (2019). Researcher Degrees of Freedom in the Psychology of Religion. The International Journal for the Psychology of Religion, 29, 230-245. https://doi.org/10.1080/10508619.2019. 1660573

Chartier, C., Kline, M., McCarthy, R., Nuijten, M., Dunleavy, D. J., \& Ledgerwood, A. (2018). The Cooperative Revolution Is Making Psychological Science Better. APS Observer, 31.

Chatard, A., Hirschberger, G., \& Pyszczynski, T. (2020). A Word of Caution about Many Labs 4: If You Fail to Follow Your Preregistered Plan, You May Fail to Find a Real Effect (Preprint). PsyArXiv. https://doi.org/10.31234/osf.io/ejubn

Claesen, A., Gomes, S. L. B. T., Tuerlinckx, F., \& Vanpaemel, W. (2019). Preregistration: Comparing Dream to Reality. PsyArXiv. https://doi.org/10.31234/osf.io/d8wex

Consortium, T. M. (2020). Quantifying Sources of Variability in Infancy Research Using the Infant-Directed-Speech Preference: Advances in Methods and Practices in Psychological Science. https://doi.org/10.1177/2515245919900809 
Corriveau, K. H., Chen, E. E., \& Harris, P. L. (2015). Judgments About Fact and Fiction by Children From Religious and Nonreligious Backgrounds. Cognitive Science, 39, 353-382. https://doi.org/10.1111/cogs.12138

Cova, F., Strickland, B., Abatista, A., Allard, A., Andow, J., Attie, M., Beebe, J., Berniūnas, R., Boudesseul, J., Colombo, M., Cushman, F., Diaz, R., N'Djaye Nikolai van Dongen, N., Dranseika, V., Earp, B. D., Torres, A. G., Hannikainen, I., HernándezConde, J. V., Hu, W., ... Zhou, X. (2018). Estimating the Reproducibility of Experimental Philosophy. Review of Philosophy and Psychology. https://doi.org/10. 1007/s13164-018-0400-9

Cristia, A., Seidl, A., Singh, L., \& Houston, D. (2016). Test-Retest Reliability in Infant Speech Perception Tasks. Infancy, 21, 648-667. https://doi.org/10.1111/infa.12127

Crüwell, S., van Doorn, J., Etz, A., Makel, M. C., Moshontz, H., Niebaum, J. C., Orben, A., Parsons, S., \& Schulte-Mecklenbeck, M. (2019). Seven Easy Steps to Open Science. Zeitschrift für Psychologie, 227, 237-248. https://doi.org/10.1027/2151-2604/ a000387

de Rijcke, S., \& Penders, B. (2018). Resist calls for replicability in the humanities. Nature, 560, 29. https://doi.org/10.1038/d41586-018-05845-z

DeHaven, A. C. (2017). Preregistration: A Plan, Not a Prison.

Dienes, Z. (2014). Using Bayes to get the most out of non-significant results. Frontiers in Psychology, 5. https://doi.org/10.3389/fpsyg.2014.00781

Doyen, S., Klein, O., Pichon, C. L., \& Cleeremans, A. (2012). Behavioral priming: It's all in the mind, but whose mind? PLoS ONE, 7, e29081. https://doi.org/10.1371/journal. pone.0029081

Dreber, A., Pfeiffer, T., Almenberg, J., Isaksson, S., Wilson, B., Chen, Y., Nosek, B. A., \& Johannesson, M. (2015). Using prediction markets to estimate the reproducibility of scientific research. Proceedings of the National Academy of Sciences of the United States of America, 112, 15343-15347. https://doi.org/10.1073/pnas.1516179112

Dubois, J., \& Adolphs, R. (2016). Building a science of individual differences from fMRI. Trends in Cognitive Sciences, 20, 425-443. https://doi.org/10.1016/j.tics.2016.03. 014

Dutilh, G., Sarafoglou, A., \& Wagenmakers, E.-J. (2019). Flexible yet fair: Blinding analyses in experimental psychology. Synthese, 1-28. https://doi.org/10.1007/s11229-01902456-7

Ebersole, C., Atherton, O., Belanger, A., Skulborstad, H., Allen, J., Banks, J., Baranski, E., Bernstein, M., Bonfiglio, D., Boucher, L., Brown, E., Budiman, N., Cairo, A., Capaldi, C., Chartier, C., Chung, J., Cicero, D., Coleman, J., Conway, J., .. Nosek, 
B. (2016). Many Labs 3: Evaluating participant pool quality across the academic semester via replication. Journal of Experimental Social Psychology, 67, 68-82.

Etz, A., Gronau, Q. F., Dablander, F., Edelsbrunner, P. A., \& Baribault, B. (2018). How to Become a Bayesian in Eight Easy Steps: An Annotated Reading List. Psychonomic Bulletin \& Review, 25, 219-234.

Evans, E. M. (2001). Cognitive and contextual factors in the emergence of diverse belief systems: Creation versus evolution. Cognitive Psychology, 217-266. https://doi.org/ 10.1006/cogp.2001.0749

Forsell, E., Viganola, D., Pfeiffer, T., Almenberg, J., Wilson, B., Chen, Y., Nosek, B. A., Johannesson, M., \& Dreber, A. (2018). Predicting replication outcomes in the Many Labs 2 study. Journal of Economic Psychology. https://doi.org/10.1016/j.joep. 2018.10 .009

Francis, G. (2013). Replication, Statistical Consistency, and Publication Bias. Journal of Mathematical Psychology, 57, 153-169. https://doi.org/10.1016/j.jmp.2013.02.003

Frank, M. C., Bergelson, E., Bergmann, C., Cristia, A., Floccia, C., Gervain, J., Hamlin, J. K., Hannon, E. E., Kline, M., Levelt, C., Lew-Williams, C., Nazzi, T., Panneton, R., Rabagliati, H., Soderstrom, M., Sullivan, J., Waxman, S., \& Yurovsky, D. (2017). A Collaborative Approach to Infant Research: Promoting Reproducibility, Best Practices, and Theory-Building. Infancy, 22, 421-435. https://doi.org/10. $1111 /$ infa. 12182

Gervais, W. M., McKee, S. E., \& Malik, S. (2020). Do Religious Primes Increase Risk Taking? Evidence Against "Anticipating Divine Protection" in Two Preregistered Direct Replications of Kupor, Laurin, and Levav (2015). Psychological Science, 31, 858-864. https://doi.org/10.1177/0956797620922477

Gervais, W. M., \& Norenzayan, A. (2012). Analytic Thinking Promotes Religious Disbelief. Science, 336, 493-496. https://doi.org/10.1126/science.1215647

Gervais, W. M., Willard, A. K., Norenzayan, A., \& Henrich, J. (2011). The Cultural Transmission of Faith: Why innate intuitions are necessary, but insufficient, to explain religious belief. Religion, 41, 389-410. https://doi.org/10.1080/0048721X.2011.604510

Gervais, W. M., Xygalatas, D., McKay, R. T., van Elk, M., Buchtel, E. E., Aveyard, M., Schiavone, S. R., Dar-Nimrod, I., Svedholm-Häkkinen, A. M., Riekki, T., Klocová, E. K., Ramsay, J. E., \& Bulbulia, J. (2017). Global evidence of extreme intuitive moral prejudice against atheists. Nature Human Behaviour, 1, 0151. https://doi. org/10.1038/s41562-017-0151

Gewin, V. (2016). Data sharing: An open mind on open data. Nature, 529, 117-119. https: //doi.org/10.1038/nj7584-117a 
Gilder, T. S. E., \& Heerey, E. A. (2018). The Role of Experimenter Belief in Social Priming. Psychological Science, 29, 403-417. https://doi.org/10.1177/0956797617737128

Gilmore, R. O., Kennedy, J. L., \& Adolph, K. E. (2018). Practical solutions for sharing data and materials from psychological research. Advances in Methods and Practices in Psychological Science, 1, 121-130. https://doi.org/10.1177/2515245917746500

Gomes, C. M., \& McCullough, M. E. (2015). The effects of implicit religious primes on dictator game allocations: A preregistered replication experiment. Journal of Experimental Psychology: General, 144, e94-e104. https://doi.org/10.1037/xge0000027

Haaf, J. M., Hoogeveen, S., Berkhout, S., Gronau, Q. F., \& Wagenmakers, E.-J. (2020). A Bayesian Multiverse Analysis of Many Labs 4: Quantifying the Evidence against Mortality Salience (Preprint). PsyArXiv. https://doi.org/10.31234/osf.io/cb9er

Haith, M. M. (1998). Who put the cog in infant cognition? Is rich interpretation too costly? Infant Behavior and Development, 21, 167-179. https://doi.org/10.1016/s01636383(98)90001-7

Hardwicke, T. E., Mathur, M. B., MacDonald, K., Nilsonne, G., Banks, G. C., Kidwell, M. C., Hofelich Mohr, A., Clayton, E., Yoon, E. J., Henry Tessler, M., Et al. (2018). Data availability, reusability, and analytic reproducibility: Evaluating the impact of a mandatory open data policy at the journal Cognition. Royal Society Open Science, 5, 180448. https://doi.org/10.31222/osf.io/39cfb

Hardwicke, T. E., Tessler, M. H., Peloquin, B., \& Frank, M. C. (2018). A Bayesian decisionmaking framework for replication. Behavioral and Brain Sciences, 41, e132. https: //doi.org/10.1017/S0140525X18000675

Hardy, A. (1981). The spiritual nature of man. A study of contemporary religious experience.

Harris, P., \& Giménez, M. (2005). Children's Acceptance of Conflicting Testimony: The Case of Death. Journal of Cognition and Culture, 5, 143-164. https://doi.org/10. $1163 / 1568537054068606$

Harris, S., Kaplan, J. T., Curiel, A., Bookheimer, S. Y., Iacoboni, M., \& Cohen, M. S. (2009). The Neural Correlates of Religious and Nonreligious Belief. PLoS ONE, 4, e7272. https://doi.org/10.1371/journal.pone.0007272

Hone, L. S. E., \& McCullough, M. E. (2015). Does religious cognition really down-regulate hand grip endurance in men? A failure to replicate. Evolution and Human Behavior, 36, 81-85. https://doi.org/10.1016/j.evolhumbehav.2014.08.007

Hoogeveen, S., Sarafoglou, A., \& Wagenmakers, E.-J. (2020). Laypeople Can Predict Which Social-Science Studies Will Be Replicated Successfully. Advances in Methods and Practices in Psychological Science, 3, 267-285. https://doi.org/10.1177/2515245920919667 
Hoogeveen, S., Snoek, L., \& van Elk, M. (2020). Religious belief and cognitive conflict sensitivity: A preregistered fMRI study. Cortex, 129, 247-265. https://doi.org/10. 1016/j.cortex.2020.04.011

Hoogeveen, S., Wagenmakers, E.-J., Kay, A. C., \& van Elk, M. (2018). Compensatory control and religious beliefs: A registered replication report across two countries. Comprehensive Results in Social Psychology, 3, 240-265. https://doi.org/10.1080/ 23743603.2019 .1684821

Huber, D. E., Potter, K. W., \& Huszar, L. D. (2019). Less "Story" and more "Reliability" in cognitive neuroscience. Cortex; a journal devoted to the study of the nervous system and behavior, 113, 347. https://doi.org/10.1016/j.cortex.2018.10.030

Inzlicht, M., McGregor, I., Hirsh, J. B., \& Nash, K. (2009). Neural markers of religious conviction. Psychological Science, 20, 385-392. https://doi.org/10.1111/j.14679280.2009.02305.x

Inzlicht, M., Tullett, A. M., \& Good, M. (2011). The need to believe: A neuroscience account of religion as a motivated process. Religion, Brain \& Behavior, 1, 192-212. https: //doi.org/10.1080/2153599x.2011.647849

Ioannidis, J. P. A. (2005). Why most published research findings are false. PLoS Medicine, 2, 696-701. https://doi.org/10.1080/09332480.2005.10722754

JASP Team. (2019). JASP (version 0.11.1)[Computer software].

John, L. K., Loewenstein, G., \& Prelec, D. (2012). Measuring the prevalence of questionable research practices with incentives for Truth-Telling. Psychological Science, 23, 524532. https://doi.org/10.1037/e632032012-001

Jong, J., Halberstadt, J., Bluemke, M., Kavanagh, C., \& Jackson, C. (2019). Death anxiety, exposure to death, mortuary preferences, and religiosity in five countries. Scientific Data, 6, 154. https://doi.org/10.1038/s41597-019-0163-x

Kavanagh, C. M., Jong, J., McKay, R., \& Whitehouse, H. (2018). Positive experiences of high arousal martial arts rituals are linked to identity fusion and costly pro-group actions. European Journal of Social Psychology, 0. https://doi.org/10.1002/ejsp. 2514

Kavanagh, C. M., \& Kapitany, R. (2017). Promoting the Benefits and Clarifying Misconceptions about Preregistration, Preprints, and Open Science for Cognitive Science of Religion. Journal for the Cognitive Science of Religion, 5, 461-481.

Kay, A. C., Gaucher, D., Napier, J. L., Callan, M. J., \& Laurin, K. (2008). God and the government: Testing a compensatory control mechanism for the support of external systems. Journal of Personality and Social Psychology, 95, 18-35. https://doi.org/ 10.1037/0022-3514.95.1.18 
Kelemen, D. (2004). Are Children "Intuitive Theists"?. Reasoning About Purpose and Design in Nature. Psychological Science, 15, 295-301. https://doi.org/10.1111/j.09567976.2004.00672.x

Kidwell, M. C., Lazarević, L. B., Baranski, E., Hardwicke, T. E., Piechowski, S., Falkenberg, L., Kennett, C., Slowik, A., Sonnleitner, C., Hess-Holden, C., Errington, T. M., Fiedler, S., \& Nosek, B. A. (2016). Badges to Acknowledge Open Practices: A Simple, Low Cost, Effective Method for Increasing Transparency. PLoS Biology, 14, e1002456. https://doi.org/10.1371/journal.pbio.1002456

Klein, O., Hardwicke, T. E., Aust, F., Breuer, J., Danielsson, H., Hofelich Mohr, A., IJzerman, H., Nilsonne, G., Vanpaemel, W., \& Frank, M. C. (2018). A practical guide for transparency in psychological science. Collabra: Psychology, 4, 1-15. https:// doi.org/10.1525/collabra.158

Klein, R., Cook, C. L., Ebersole, C. R., Vitiello, C. A., Nosek, B. A., Chartier, C. R., Christopherson, C. D., Clay, S., Collisson, B., Crawford, J., Cromar, R., Vidamuerte, D., Gardiner, G., Gosnell, C., Grahe, J. E., Hall, C., Joy-Gaba, J. A., Legg, A. M., Levitan, C., ... Ratliff, K. A. (2019). Many Labs 4: Failure to Replicate Mortality Salience Effect With and Without Original Author Involvement (Preprint). PsyArXiv. https://doi.org/10.31234/osf.io/vef2c

Klein, R., Ratliff, K., Vianello, M., Adams, R. B., Jr., Bahńik, S., Bernstein, M., Bocian, K., Brandt, M., Brooks, B., Brumbaugh, C., Cemalcilar, Z., Chandler, J., Cheong, W., Davis, W., Devos, T., Eisner, M., Frankowska, N., Furrow, D., Galliani, E. M., ... Nosek, B. (2014). Investigating variation in replicability: A "Many Labs" replication project. Social Psychology, 45, 142-152. https:// doi.org/10.1027/1864-9335/ a000178

Klein, R., Vianello, M., Hasselman, F., Adams, B., Adams, R., Alper, S., Aveyard, M., Axt, J., Bahník, S., Batra, R., Berkics, M., Bernstein, M., Berry, D., Bialobrzeska, O., Binan, E., Bocian, K., Brandt, M., Busching, R., Redei, A., ... Nosek, B. (2018). Many Labs 2: Investigating variation in replicability across sample and setting. $A d-$ vances in Methods and Practices in Psychological Science, 1, 443-490.

Konvalinka, I., Xygalatas, D., Bulbulia, J., Schjødt, U., Jegindø, E.-M., Wallot, S., Van Orden, G., \& Roepstorff, A. (2011). Synchronized arousal between performers and related spectators in a fire-walking ritual. Proceedings of the National Academy of Sciences, 108, 8514-8519. https://doi.org/10.1073/pnas.1016955108

Kupor, D. M., Laurin, K., \& Levav, J. (2015). Anticipating Divine Protection? Reminders of God Can Increase Nonmoral Risk Taking. Psychological Science, 26, 374-384. https://doi.org/10.1177/0956797614563108 
Leshinskaya, A., Contreras, J. M., Caramazza, A., \& Mitchell, J. P. (2017). Neural representations of belief concepts: A representational similarity approach to social semantics. Cerebral Cortex, 27, 344-357. https://doi.org/10.1093/cercor/bhw401

Luhrmann, T. M. (2005). The Art of Hearing God: Absorption, Dissociation, and Contemporary American Spirituality. Spiritus: A Journal of Christian Spirituality, 5, 133-157. https://doi.org/10.1353/scs.2006.0014

Luhrmann, T. M. (2012). When God talks back: Understanding the American evangelical relationship with God. New York, Vintage Books.

Luhrmann, T. M., Padmavati, R., Tharoor, H., \& Osei, A. (2015). Hearing Voices in Different Cultures: A Social Kindling Hypothesis. Topics in Cognitive Science, 7, 646-663. https://doi.org/10.1111/tops.12158

MacCoun, R., \& Perlmutter, S. (2015). Hide Results to Seek the Truth. Nature, 526, 187189.

Makel, M. C., Plucker, J. A., \& Hegarty, B. (2012). Replications in Psychology Research: How Often Do They Really Occur? Perspectives on Psychological Science, 7, 537542. https://doi.org/10.1177/1745691612460688

Makris, N., \& Pnevmatikos, D. (2007). Children's understanding of human and supernatural mind. Cognitive Development, 22, 365-375. https://doi.org/10.1016/j. cogdev.2006.12.003

McCullough, M. E., Carter, E. C., DeWall, C. N., \& Corrales, C. M. (2012). Religious cognition down-regulates sexually selected, characteristically male behaviors in men, but not in women. Evolution and Human Behavior, 33, 562-568. https://doi.org/ 10.1016/j.evolhumbehav.2012.02.004

McPhetres, J. (2018). Religiosity and Confirmation Bias or: How I learned to stop worrying and love preregistered direct replications. OSF Preprints. https://doi.org/10.31219/ osf.io/g7apd

Moshontz, H., Campbell, L., Ebersole, C. R., IJzerman, H., Urry, H. L., Forscher, P. S., Grahe, J. E., McCarthy, R. J., Musser, E. D., Antfolk, J., Castille, C. M., Evans, T. R., Fiedler, S., Flake, J. K., Forero, D. A., Janssen, S. M. J., Keene, J. R., Protzko, J., Aczel, B., .. Chartier, C. R. (2018). The Psychological Science Accelerator: Advancing psychology through a distributed collaborative network. Advances in Methods and Practices in Psychological Science, 1, 501-515. https://doi.org/10. $1177 / 2515245918797607$

Munafò, M. R., \& Smith, G. D. (2018). Robust research needs many lines of evidence. Nature, 553, 399-401. https://doi.org/10.1038/d41586-018-01023-3 
Nakagawa, S., \& Hauber, M. E. (2011). Great challenges with few subjects: Statistical strategies for neuroscientists. Neuroscience \& Biobehavioral Reviews, 35, 462-473. https://doi.org/10.1016/j.neubiorev.2010.06.003

Neubauer, R. L. (2014). Prayer as an interpersonal relationship: A neuroimaging study. Religion, Brain \& Behavior, 4, 92-103. https://doi.org/10.1080/2153599X.2013. 768288

Norenzayan, A., Shariff, A. F., Gervais, W. M., Willard, A. K., McNamara, R. A., Slingerland, E., \& Henrich, J. (2016). The cultural evolution of prosocial religions. Behavioral and Brain Sciences, 39. https://doi.org/10.1017/S0140525X14001356

Nosek, B. A., Alter, G., Banks, G. C., Borsboom, D., Bowman, S. D., Breckler, S. J., Buck, S., Chambers, C. D., Chin, G., Christensen, G., Contestabile, M., Dafoe, A., Eich, E., Freese, J., Glennerster, R., Goroff, D., Green, D. P., Hesse, B., Humphreys, M., ... Yarkoni, T. (2015). Promoting an Open Research Culture. Science, 348, 14221425. https://doi.org/10.1126/science.aab2374

Nosek, B. A., \& Lindsay, D. S. (2018). Preregistration Becoming the Norm in Psychological Science. APS Observer, 31.

Nosek, B. A., Ebersole, C. R., DeHaven, A. C., \& Mellor, D. T. (2018). The Preregistration Revolution. Proceedings of the National Academy of Sciences, 115, 2600-2606. https: //doi.org/10.1073/pnas.1708274114

Nosek, B. A., \& Errington, T. M. (2017). Making sense of replications. eLife, 6, e23383. https://doi.org/10.7554/eLife.23383

Nosek, B. A., \& Errington, T. M. (2020). What is replication? PLOS Biology, 18, e3000691. https://doi.org/10.1371/journal.pbio.3000691

Open Science Collaboration. (2012). An Open, Large-Scale, Collaborative Effort to Estimate the Reproducibility of Psychological Science. Perspectives on Psychological Science, 7, 657-660. https://doi.org/10.1177/1745691612462588

Open Science Collaboration, T. (2015). Estimating the reproducibility of psychological science. Science, 349, aac4716. https://doi.org/10.1126/science.aac4716

Pan, D. (2017). Is Chinese Culture Dualist? An Answer to Edward Slingerland from a Medical Philosophical Viewpoint. Journal of the American Academy of Religion, 85, 1017-1031. https://doi.org/10.1093/jaarel/lfx028

Pashler, H., Rohrer, D., \& Harris, C. R. (2013). Can the goal of honesty be primed? Journal of Experimental Social Psychology, 49, 959-964. https://doi.org/10.1016/j.jesp. 2013.05.011

Payne, G., \& Williams, M. (2005). Generalization in Qualitative Research. Sociology-the Journal of The British Sociological Association, 39, 295-314. https://doi.org/10. $1177 / 0038038505050540$ 
Peels, R., \& Bouter, L. (2018a). The possibility and desirability of replication in the humanities. Palgrave Communications, 4, 95. https://doi.org/10.1057/s41599-018-0149-x

Peels, R., \& Bouter, L. (2018b). Replication in Humanities Just as Desirable as in Sciences.

Potter, K. W., Huszar, L. D., \& Huber, D. E. (2018). Does inhibition cause forgetting after selective retrieval? A reanalysis and failure to replicate. Cortex, 104, 26-45. https://doi.org/10.1016/j.cortex.2018.03.026

Power, E. A. (2017). Discerning devotion: Testing the signaling theory of religion. Evolution and Human Behavior, 38, 82-91. https://doi.org/10.1016/j.evolhumbehav.2016.07. 003

Purzycki, B. G., Ross, C. T., Apicella, C., Atkinson, Q. D., Cohen, E., McNamara, R. A., Willard, A. K., Xygalatas, D., Norenzayan, A., \& Henrich, J. (2018). Material security, life history, and moralistic religions: A cross-cultural examination. PLoS ONE, 13, e0193856. https://doi.org/10.1371/journal.pone.0193856

Rouder, J. N. (2014). Optional stopping: No problem for Bayesians. Psychonomic Bulletin \&5 Review, 21, 301-308. https://doi.org/10.3758/s13423-014-0595-4

Rowhani-Farid, A., Aldcroft, A., \& Barnett, A. G. (2020). Did awarding badges increase data sharing in BMJ Open ? A randomized controlled trial. Royal Society Open Science, 7, 191818. https://doi.org/10.1098/rsos.191818

Sanchez, C., Sundermeier, B., Gray, K., \& Calin-Jageman, R. J. (2017). Direct replication of Gervais \& Norenzayan (2012): No evidence that analytic thinking decreases religious belief. PLoS ONE, 12, e0172636. https://doi.org/10.1371/journal.pone.0172636

Schjoedt, U., \& Bulbulia, J. (2011). The need to believe in conflicting propositions. Religion, Brain \& Behavior, 1, 236-239. https://doi.org/10.1080/2153599X.2011.647857

Schjoedt, U., Sørensen, J., Nielbo, K. L., Xygalatas, D., Mitkidis, P., \& Bulbulia, J. (2013). Cognitive resource depletion in religious interactions. Religion, Brain and Behavior, 3, 39-55. https://doi.org/10.1080/2153599X.2012.736714

Schjoedt, U., Stødkilde-Jørgensen, H., Geertz, A. W., Lund, T. E., \& Roepstorff, A. (2011). The power of charisma-perceived charisma inhibits the frontal executive network of believers in intercessory prayer. Social Cognitive and Affective Neuroscience, 6, 119-127. https://doi.org/10.1093/scan/nsq023

Schjoedt, U., Stødkilde-Jørgensen, H., Geertz, A. W., \& Roepstorff, A. (2009). Highly religious participants recruit areas of social cognition in personal prayer. Social Cognitive and Affective Neuroscience, 4, 199-207. https://doi.org/10.1093/scan/nsn050

Schjoedt, U., \& van Elk, M. (2019). The Neuroscience of Religion (J. Barrett, Ed.). In J. Barrett (Ed.), Oxford Handbook of the Cognitive Science of Religion. Oxford, UK, Oxford Univerity Press. 
Schmidt, S. (2009). Shall we Really do it Again? The Powerful Concept of Replication is Neglected in the Social Sciences. Review of General Psychology, 13, 90-100. https: //doi.org/10.1037/a0015108

Schönbrodt, F. D., \& Perugini, M. (2013). At what sample size do correlations stabilize? Journal of Research in Personality, 47, 609-612. https://doi.org/10.1016/j.jrp. 2013.05 .009

Schott, E., Rhemtulla, M., \& Byers-Heinlein, K. (2018). Should I test more babies? Solutions for transparent data peeking. Infant Behavior and Development. https://doi.org/ 10.31234/osf.io/gxfaj

Shanks, D. R., Newell, B. R., Lee, E. H., Balakrishnan, D., Ekelund, L., Cenac, Z., Kavvadia, F., \& Moore, C. (2013). Priming intelligent behavior: An elusive phenomenon. PLoS ONE, 8, e56515. https://doi.org/10.1371/journal.pone.0056515

Shariff, A. F., \& Norenzayan, A. (2007). God Is Watching You: Priming God Concepts Increases Prosocial Behavior in an Anonymous Economic Game. Psychological Science, 18, 803-809. https://doi.org/10.1111/j.1467-9280.2007.01983.x

Shariff, A. F., Willard, A. K., Andersen, T., \& Norenzayan, A. (2016). Religious priming: A meta-analysis with a focus on prosociality. Personality and Social Psychology Review, 20, 27-48. https://doi.org/10.1177/1088868314568811

Slingerland, E., \& Chudek, M. (2011). The prevalence of mind-body dualism in early China. Cognitive Science, 35, 997-1007. https://doi.org/10.1111/j.1551-6709.2011.01186.x

Slingerland, E., \& Collard, M. (2011). Creating consilience: Integrating the sciences and the humanities. Oxford University Press. https://doi.org/10.1093/acprof:oso/ 9780199794393.001.0001

Smith, S. M., Beckmann, C. F., Andersson, J., Auerbach, E. J., Bijsterbosch, J., Douaud, G., Duff, E., Feinberg, D. A., Griffanti, L., Harms, M. P., Kelly, M., Laumann, T., Miller, K. L., Moeller, S., Petersen, S., Power, J., Salimi-Khorshidi, G., Snyder, A. Z., Vu, A. T., ... Glasser, M. F. (2013). Resting-state fMRI in the Human Connectome Project. NeuroImage, 80, 144-168. https://doi.org/10.1016/j.neuroimage.2013.05. 039

Snoek, L., van der Miesen, M. M., Beemsterboer, T., van der Leij, A., Eigenhuis, A., \& Scholte, H. S. (2020). The Amsterdam Open MRI Collection, a set of multimodal MRI datasets for individual difference analyses. bioRxiv. https://doi.org/10.1101/ 2020.06.16.155317

Spellman, B. A. (2015). A Short (Personal) Future History of Revolution 2.0. Perspectives on Psychological Science, 10, 886-899. https://doi.org/10.1177/1745691615609918

Sterelny, K. (2018). Religion re-explained. Religion, Brain \& Behavior, 8, 406-425. https: //doi.org/10.1080/2153599X.2017.1323779 
Szucs, D., \& Ioannidis, J. P. A. (2017). Empirical Assessment of Published Effect Sizes and Power in the Recent Cognitive Neuroscience and Psychology Literature. PLoS Biology, 15, e2000797. https://doi.org/10.1371/journal.pbio.2000797

Tamminen, K. A., \& Poucher, Z. A. (2018). Open science in sport and exercise psychology: Review of current approaches and considerations for qualitative inquiry. Psychology of Sport and Exercise, 36, 17-28. https://doi.org/10.1016/j.psychsport.2017.12.010

Taves, A. (1999). Fits, trances, $\&$ visions: Experiencing religion and explaining experience from Wesley to James. Princeton University Press. https://doi.org/10.2307/2674486

Taves, A. (2010). No Field Is an Island: Fostering Collaboration between the Academic Study of Religion and the Sciences. Method 8 Theory in the Study of Religion, 22, 170-188. https://doi.org/10.1163/157006810X512356

Tierney, W., Hardy, J., III, Ebersole, C., Viganola, D., Clemente, E., Gordon, E., Hoogveveen, S., Haaf, J. M., Dreber, A., Johannesson, M., Pfeiffer, T., Chapman, H., Gantman, A., Vanaman, M., DeMarree, K., Igou, E., Wylie, J., Storbeck, J., Andreychik, M., ... Uhlmann, E. L. (2021). A creative destruction approach to replication: Implicit work and sex morality across cultures. Journal of Experimental Social Psychology, 93, 104060.

Uhlmann, E. L., Poehlman, T. A., \& Bargh, J. A. (2009). American moral exceptionalism, In Social and psychological bases of ideology and system justification. New York, NY, Oxford University Press.

Uhlmann, E. L., Poehlman, T. A., Tannenbaum, D., \& Bargh, J. A. (2011). Implicit Puritanism in American moral cognition. Journal of Experimental Social Psychology, 47, 312-320. https://doi.org/10.1016/j.jesp.2010.10.013

van Doorn, J., van den Bergh, D., Böhm, U., Dablander, F., Derks, K., Draws, T., Etz, A., Evans, N. J., Gronau, Q. F., Haaf, J. M., Et al. (2020). The JASP guidelines for conducting and reporting a Bayesian analysis. Psychonomic Bulletin 6 Review, $1-14$.

van Elk, M. (2019). Replication and Open Science in the Psychology of Religion: Editorial to the Special Issue. The International Journal for the Psychology of Religion, 29, 227-229. https://doi.org/10.1080/10508619.2019.1687189 _eprint: https://doi.org/10.1080/10508619.2019.1687189

van Elk, M., Rutjens, B. T., van der Pligt, J., \& van Harreveld, F. (2016). Priming of supernatural agent concepts and agency detection. Religion, Brain $\&$ Behavior, 6 , $4-33$.

van Elk, M., \& Snoek, L. (2020). The relationship between individual differences in grey matter volume and religiosity and mystical experiences: A pre-registered voxel-based 
morphometry study. European Journal of Neuroscience, 51, 850-865. https://doi. org/10.1111/ejn.14563

van Elk, M., \& Wagenmakers, E.-J. (2017). Can the experimental study of religion be advanced using a Bayesian predictive framework? Religion, Brain \& Behavior, 7, 331-334. https://doi.org/10.1080/2153599X.2016.1249915

van 't Veer, A. E., \& Giner-Sorolla, R. (2016). Pre-registration in Social Psychology - A Discussion and Suggested Template. Journal of Experimental Social Psychology, 67, 2-12. https://doi.org/10.31234/osf.io/4frms

Vazire, S. (2018). Implications of the Credibility Revolution for Productivity, Creativity, and Progress. Perspectives on Psychological Science, 13, 411-417. https://doi.org/ 10.31234/osf.io/2yphf

Wagenmakers, E.-J., Gronau, Q. F., \& Vandekerckhove, J. (2019). Five Bayesian intuitions for the stopping rule principle. https://doi.org/10.31234/osf.io/5ntkd

Wagenmakers, E.-J., Wetzels, R., Borsboom, D., \& van der Maas, H. L. J. (2011). Why psychologists must change the way they analyze their data: The case of psi: Comment on Bem (2011). Journal of Personality and Social Psychology, 100, 426-432. https: //doi.org/10.1037/a0022790

Wagenmakers, E.-J., Wetzels, R., Borsboom, D., van der Maas, H. L. J., \& Kievit, R. A. (2012). An agenda for purely confirmatory research. Perspectives on Psychological Science, 7, 627-633. https://doi.org/10.1177/1745691612463078

Wagenmakers, E.-J., Love, J., Marsman, M., Jamil, T., Ly, A., Verhagen, J., Selker, R., Gronau, Q. F., Dropmann, D., Boutin, B., Meerhoff, F., Knight, P., Raj, A., van Kesteren, E.-J., van Doorn, J., Šmíra, M., Epskamp, S., Etz, A., Matzke, D., ... Morey, R. D. (2018). Bayesian inference for psychology. Part II: Example applications with JASP. Psychonomic Bulletin \& Review, 25, 58-76. https://doi.org/10. 3758/s13423-017-1323-7

Wagenmakers, E.-J., Marsman, M., Jamil, T., Ly, A., Verhagen, J., Love, J., Selker, R., Gronau, Q. F., Šmíra, M., Epskamp, S., Matzke, D., Rouder, J. N., \& Morey, R. D. (2018). Bayesian inference for psychology. Part I: Theoretical advantages and practical ramifications. Psychonomic Bulletin \& Review, 25, 35-57. https://doi.org/10. 3758/s13423-017-1343-3

Wagge, J. R., Brandt, M. J., Lazarevic, L. B., Legate, N., Christopherson, C., Wiggins, B., \& Grahe, J. E. (2019). Publishing Research With Undergraduate Students via Replication Work: The Collaborative Replications and Education Project. Frontiers in Psychology, 10. https://doi.org/10.3389/fpsyg.2019.00247 
White, C. J. M., Norenzayan, A., \& Schaller, M. (2018). The Content and Correlates of Belief in Karma Across Cultures. Personality and Social Psychology Bulletin, 18. https://doi.org/10.1177/0146167218808502

Whitehouse, H., \& Lanman, J. A. (2014). The Ties That Bind Us: Ritual, Fusion, and Identification. Current Anthropology, 55, 674-695. https://doi.org/10.1086/678698

Wilkinson, M. D., Dumontier, M., Aalbersberg, I. J., Appleton, G., Axton, M., Baak, A., Blomberg, N., Boiten, J., da Silva Santos, L. B., Bourne, P. E., Bouwman, J., Brookes, A. J., Clark, T., Crosas, M., Dillo, I., Dumon, O., Edmunds, S., Evelo, C. T., Finkers, R., .. Mons, B. (2016). The FAIR Guiding Principles for Scientific Data Management and Stewardship. Scientific Data, 3. https://doi.org/10.1038/ sdata.2016.18

Wimber, M., Alink, A., Charest, I., Kriegeskorte, N., \& Anderson, M. C. (2015). Retrieval induces adaptive forgetting of competing memories via cortical pattern suppression. Nature Neuroscience, 18, 582-589. https://doi.org/10.1038/nn.3973

Wright, R. (2010). The evolution of God: The origins of our beliefs. Hachette UK.

Yeung, A. W. K. (2017). Do Neuroscience Journals Accept Replications? A Survey of Literature. Frontiers in Human Neuroscience, 11. https://doi.org/10.3389/fnhum.2017. 00468

Yong, E. (2012). A failed replication draws a scathing personal attack from a psychology professor. Discover Magazine. 